\title{
How to take into account vulnerability in aid allocation criteria and lack of human capital as well: improving the performance based allocation
}

\author{
Patrick Guillaumont \\ Sylviane Guillaumont Jeanneney \\ Laurent WAGNER
}

\footnotetext{
C Patrick Guillaumont is President of the Fondation pour les Études et Recherches sur le Développement International (Ferdi). He is also Professor Emeritus at the University of Auvergne, member of Cerdi (Centre d'études et de recherches sur le développement international) that he founded in 1976, and director of the Revue d'économie du développement.

C Sylviane Gulllaumont Jeanneney is Emeritus Professor at the University of Auvergne, researcher at Cerdi and consultant at Ferdi. She is also member of the Board of the French Development Agency. Her main research interests are development economics, international cooperation, exchange rate, monetary and fiscal policy and environmental issues.

Laurent Wagner is PhD student at Cerdi.
}

\begin{abstract}
This paper considers why and how the PBA (performance based allocation) used in multilateral development banks and in particular at IDA, could be improved by taking the structural vulnerability of eligible countries into account. . This improvement is needed for several reasons. The PBA relies on a debatable definition of performance. It does not meet the equity concern raised by the existence of structural handicaps to growth, in particular vulnerability and lack of human capital. It neglects the lessons of the aid effectiveness literature, in particular on the shock dampening effect of aid.


Finally, it suffers from some opacity due to the various floors, caps and exceptions brought in its application, in particular for conflict prone countries, treated only in a curative manner.

An augmented PBA is first proposed, taking into account structural vulnerability and lack of human capital in the measurement of performance, keeping the same structure than the present IDA formula and giving the unchanged weights to the other two criteria, population and income per capita. The present measure of performance by a country policy rating (CPR) is replaced by a weighted average of CPR, an index of structural economic vulnerability and an index of low human assets, the last two indices being those used at the UN for the identification of the least developed countries. As far as CPR is affected by the structural economic vulnerability and the lack of human capital, this weighted average can be considered as an augmented measure of performance. Simulations are run, successively using weights corresponding to an estimated impact of vulnerability and weights more in accordance with an equity concern. Moreover, to avoid floors and caps, simulations are made with I population exponents lower than one (actually o.8).

In a second time, departing more largely from the existing formula, a new set of formulas are presented, which aim at balancing effectiveness and equity criteria. The results show how it is possible to maintain or increase the share of target groups of countries, such as Sub-Sahara Africa or post-conflict and reengaging states, in a continuous and transparent manner,.

The paper also briefly considers other changes likely to improve the consistency of the present formula: one would be to use an extended CPR integrating the assessment of policy of post-conflict and of other countries; another one would be to set up a "crisis prevention window" besides the crisis response window that is presently considered by IDA.

\section{Introduction}

While the consequences of the recent economic crisis on the poorest countries -by no means responsible for it- appear to have been strong, discussions have been engaged on the replenishment of resources of the main multilateral development banks. Linked to this replenishment is the agreement of the banks governors on the principles determining the allocation of aid among the eligible countries. In the main multilateral development banks (MDBs) these principles are summarized in a formula, called "performance based allocation", PBA. With some small differences from one MDB to the other, the formula is intended to determine the amount of aid per capita received by a country according to two main indicators, income per capita and 
"performance", the latter having an overwhelming weight. There has been a growing discontent among researchers and policy makers about the PBA formula, as it is presently designed, in particular because it ignores the need of assistance generated by the economic vulnerability of countries and simultaneously by a low level of human capital. However there is a high risk it will be maintained nearly unchanged, partly as a result of a lack of clear proposals of reform.

The detrimental consequences of the structural economic vulnerability of developing countries, notably the least developed countries (LDCs), have received great concern in the academic literature for a long time (see a survey in Guillaumont, 2009a and 2009b). Therefore it is somewhat amazing that the multilateral development banks (MDBs) do not take this feature for designing the principles of the geographical allocation of their aid ${ }^{2}$. However ideas are moving. In particular the African Development Bank has taken the initiative to commission a study to examine how such a reform could be implemented (Guillaumont et al., 2009). Moreover and noticeably enough, the principle of including structural economic vulnerability among the aid allocation criteria has been endorsed in several international documents ${ }^{2}$.

This article first explains why it would be legitimate to take into account the structural vulnerability of developing countries in aid allocation with regard to effectiveness and equity principles. Then various solutions are presented to improve the "performance based allocation" (PBA) used by multilateral development banks. We mainly illustrate our propositions by the case of IDA's allocations.

\section{Why to take into account structural vulnerability and revise the present PBA}

Six main reasons for improving the present PBA by integrating a vulnerability index can be identified.

\section{What performance means}

No doubt the success of the PBA has come from the word "performance". Everybody wants developing countries to perform and aid to support their performance. The problem lies in the ambiguity of the word "performance" or more precisely in the fact that the performance of the PBA formula is far from the genuine meaning of performance. Performance refers to the results or outcomes obtained by a country in a given initial situation, whereas PBA performance refers to a subjective assessment of the country policy, indeed a different animal (on the meaning and measurement of performance: Guillaumont and Chauvet, 2001, Guillaumont and Guillaumont Jeanneney 1988).

\footnotetext{
1. One exception is the Caribbean Development Bank.

2. One is the UN Secretary General report to the ECOSOC Development Cooperation Forum in 2008. Another is the final Declaration of the Joint Ministerial Forum on Debt Sustainability organized by the Commonwealth Secretariat and the Organisation internationale de la francophonie in April 2009. Moreover a key message of the Consultative Workshop on Policy Options to Address the Looming Debt Problems of Commonwealth Small Vulnerable Economies (Kingston, Jamaica, 27th September 2010) was "that the reform of aid allocation criteria to include consideration of structural handicaps to growth (vulnerability to exogenous shocks and low human capital) should be linked (for presentation purposes) to the achievement of MDGs and the provision/maintenance of social safety nets. Given the focus of the international community on the achievement of MDGs this would be critical to gain traction and support for this reform". Finally the Franc Zone Ministers of Finance in their meeting of October 2010 have asked that the criteria of vulnerability be taken into account by MDBs and bilateral donors.
} 
This assessment is done thanks to a Country Policy Rating the main element of which is the "Country Policy and Institutional Assessment" (CPIA), which is the aggregation of indicators representative of economic and social policies, institutions and governance ${ }^{3}$. The CPIA is separately measured by the World Bank and by the African Bank of Development for their own usage. Although the CPIA has strongly been debated and criticized (for instance Michailof, 2005), we do not conclude that it should be deleted in the formula, but we argue that, even reformed, it should not be given the overwhelming weight it receives today. A main concern comes from that it is a subjective assessment, with regard to uniform norms, what does not particularly fit the principles of alignment and ownership, adopted by the Paris Declaration, reformulated in Accra Conference, often reaffirmed in international meetings, and intended to increase aid effectiveness. Moreover CPIA is not stable, what makes the allocation volatile and hardly predictable (while predictability is another concern of international community). The AfDF study evidences the strong impact of a small change in a country CPIA on the amount of aid allocated to this country (Guillaumont et al. 2009). Furthermore as CPIA is generally improving when exogenous economic conditions are favourable, it induces pro-cyclical aid allocations, what means leading to less aid when the countries need the more (see Guillaumont et al. 2010...).

The CPIA has been initially retained as a major aid allocation criterion because it was supposed to correspond to a factor of aid effectiveness for growth, a result that has been found not really significant in the academic literature (see for instance Hansen and Tarp 2001, Roodman 2007, Easterly et al 2004). It has simultaneously been used to assess the selectivity of donors or the quality of their geographical aid allocation. (Amprou et al. 2007). The main single reason to maintain this criterion has been a feeling that helping those countries considered as "good guys" will push all the countries to become more virtuous. To be underlined, referring to an improved measure of performance that takes into account the structural handicaps the developing countries are facing would maintain the present signal effect of the PBA, but also make it more acceptable by the recipient countries. Thus it would enhance their commitment to good policies.

\section{Taking into account the structural handicaps to development, in particular vulnerability}

Why first not to consider that aid allocation should be equitable? (Roemer J.E. 1998, World Bank 2006). Of course there are many views on what is equity. A now commonly accepted meaning is related to equal opportunities (Rawls 1971). Developing the idea of Rawls, Amartya Sen has shown that assessing people's advantage and disadvantage involves looking at people's ability to do or be what they have reason to value, or the "capabilities" of each person. The capability perspective leads to consider that low personal income is only one among several factors that influence the deprivation of basic capabilities ${ }^{4}$. Transposing the capability perspective to the country level in order to determine aid allocation involves taking into account the structural obstacles to growth each country faces. It is a dynamic design of justice, with regard to growth prospects. The present PBA formula as it refers only to income per capita and to the quality of policies fails to take into account any of the main structural handicaps of development, such as

3. An indicator of the success of the projects initiated by the development bank is added to the CPIA.

4. The publications of Sen are multiple; for a recent one, see The Idea of Justice, Penguin Books, London 2009. 
those considered at the UN for the identification of the LDCs. These are the economic vulnerability and the lack of human capital faced by a country independently of his present will. This structural vulnerability is due to the recurrence of exogenous shocks, either natural or external (droughts as well commodity prices instability) and the exposure to these shocks (small size, remoteness, structure of production). And a low human capital exacerbates the detrimental effects of recurrent shocks (Guillaumont 2009b).

\section{Drawing the lessons of aid effectiveness literature}

While the impact of governance on aid effectiveness has been repeatedly debated in the academic literature, there is a consensus to consider that aid effectiveness depends on the specific features of the recipient countries. Among those features, vulnerability to exogenous shocks has received in the literature an increasing attention, not always fully understood in policy circles. Indeed shocks and vulnerability are negative factors of development, whereas good governance is a positive factor, but both are, at the same time, factors increasing aid effectiveness. Indeed a major reason why aid can have a macro-economic impact on growth and development is due to its stabilizing impact: it dampens the negative impact of shocks (Guillaumont and Chauvet 2001, Chauvet and Guillaumont 2004, 2009, Collier and Goderik 2009). In this perspective, aid should not be pro-cyclical, a risk enhanced by the use of CPIA as the sole criterion of aid allocation, as mentionned previously.

Thus, for effectiveness reasons, and not only for equity reasons, it is not legitimate to omit structural economic vulnerability to exogenous shocks in the aid allocation criteria.

\section{Avoiding a double punishment... \\ and distinguishing between aid allocation and aid modalities}

The fact to consider only the quality of governance and policy as a criterion of aid allocation has an unexpected and unfair consequence. Populations suffering from bad government and policies are at the time penalized by aid allocation. They are punished twice...thanks to aid donors!

It does not mean that aid policy should not take the quality of governance and policy into account, but that it should do it mainly through aid modalities rather than through aid volume (for instance, by giving less budget support and more project support, including through private channels).

\section{Enhancing transparency and consistency by making the rule general and effective}

Facing the difficulty to rigorously implement the PBA, the MDBs have been led to multiply the exceptions by the way of caps and floors (in order to take the disadvantage of a small size into account) and by the way of a special treatment applied to some countries. In particular, when the level of the Country Policy Rating (CPR) has reached very low levels because of situations of chaos or civil conflict, what is the case of the so-called post-conflict and reengaging states at World Bank, fragile states at African Bank of Development, a special treatment has been designed for them. 
A first consequence of these practices is the lack of transparency of the allocation process. In the peculiar case of IDA, it is not possible to exactly replicate country allocations outside the World Bank, even when one applies the principles of allocation as they are explained in the official documents 5 .

A second one is that aid allocation may be in conflict with the performance based principle. Special treatment to post-conflict and reengaging countries is leading to an allocation to these countries higher than to the other countries with the same or even higher CPR. This can be illustrated by the following graph (figure 1) which presents the IDA allocation per capita as a function of the CPR. Moreover some very small countries receive an allocation per capita quite higher then other countries with similar CPR, thanks to the application of floor or base allocation: for instance Tonga, Vanuatu and Sao-Tome and Principe with a CPR around 3.2. On the opposite India to which a cap is applied receive a very small allocation per capita with regard to its CPR. These results may be legitimate, but for reasons not made explicit in the formula. They clearly show that the PBA is not really effective since the allocation does not continuously decrease as a function of the CPR, mainly as a result of the treatment of the post conflict and reengaging countries.

Figure 1. IDA aid allocation in 2009 as a function of the agreed measure of performance

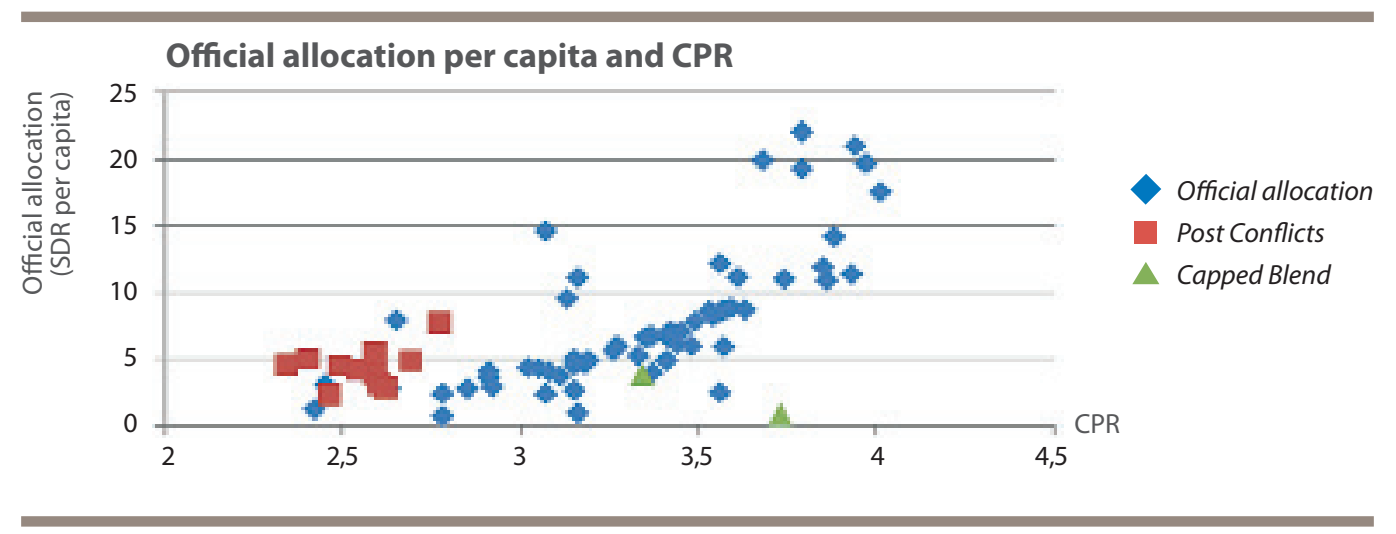

Let us now consider the relationship between CPR and aid per capita at the quintile level (figure 2). The curve of allocations appears nearly horizontal for the three first quintiles, then increasing. The curve of commitments evidences some difference with that of allocations, the third quintile even being at a lower level than the second quintile. The curve of disbursements appears even more different with the higher aid levels observed at the lowest three quintile of CPR and the lowest level of aid at the fourth quintile of CPR But as far one year disbursements may depend on commitments of several previous year, the discrepancy cannot be clearly as a

\footnotetext{
5. The major problems when one tries to replicate the IDA allocation process is that the Post Conflict Performance Index (PCPI) is still confidential. This last one is used to calculate allocations during each year of the phase-out period (after four years for post-conflict countries and two years for reengaging ones), the premium (calculated as a difference between allocations computed using the PCPI and those computed using the PBA formula) is gradually reduced. Without this index, one is not able to compute the post conflict and re-engaging premium. This premium has to be separated from the starting envelop before the allocation process begins. Benjamin Leo (2010) from the Center for Global Development has met a similar problem as he writes: "This paper has re-created the PBA using the (IDA) methodology to simulate the results. While every effort was made to ensure consistency with IDA's actual allocation system, undoubtedly there are country-specific variations compared to IDA's internally generated and authorative figures. On average , final country-specific allocations differed by approximately 6 per cent compared to those published publicly by World Bank Staff"( p. 6). The difficulty to replicate on a several year basis is reinforced by the fact that the allocations of the previous years are still disclosed.
} 
deviation from the allocation rule ${ }^{6}$. Anyway not only aid allocation does not globally reflect the impact that the formula intends to give to the CPR, but also aid commitments seem to deviate even more from the principle of an allocation according to the CPR.

The final result of the allocation process is a purely curative, not at all preventive, treatment of fragility, in a framework rather opaque and not fully consistent. The other exceptions, designed to address the case of very large or very small countries, have amplified opacity and lack of consistency due to thresholds effects

Figure 2. Aid per capita as a function of CPR at the quintile level: allocations, commitments and disbursements compared

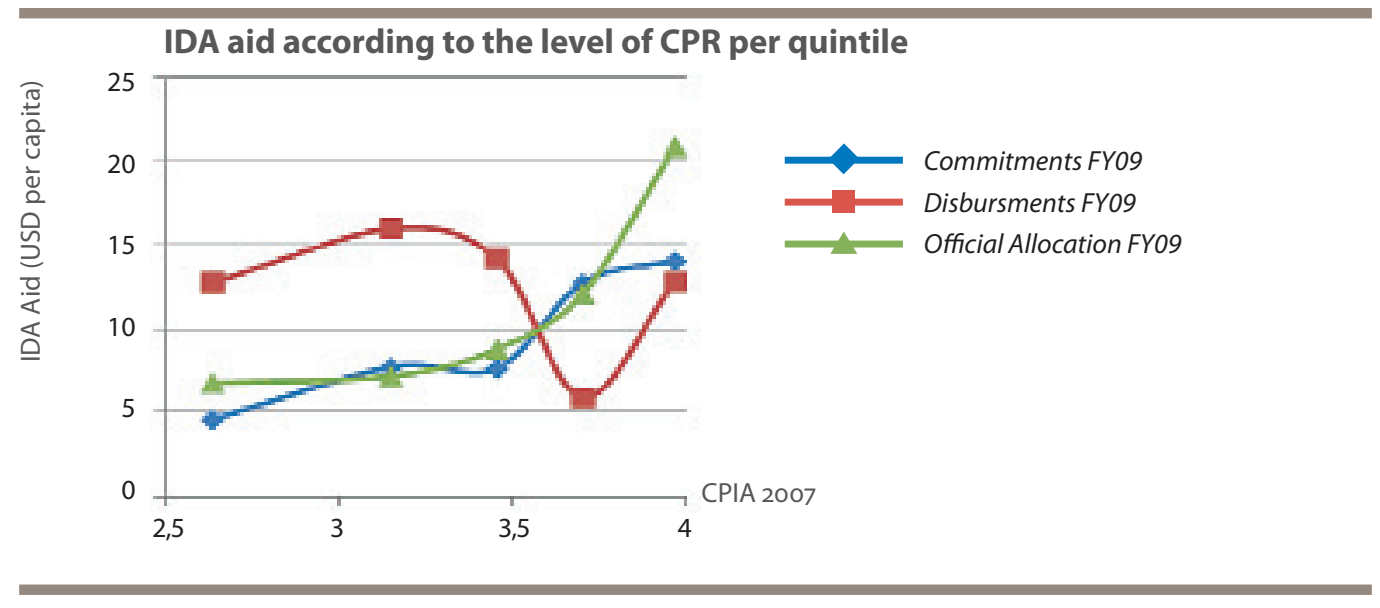

\section{Making the allocation more stable}

Small changes in the CPIA have amplified effects on aid allocation, making it volatile, as evidenced in the ADF study (Guillaumont et al 2009). Aid volatility is often prosecuted to be detrimental to policy management and growth. Taking into account the structural handicaps, the indicators of which slowly change, anyway quite slower than the policy indicators, would reduce the volatility in aid allocation.

\section{Main lines of possible reforms}

In the following, we examine how to address the previous issues and consequently improve the PBA formula. Briefly stated the present PBA could much better meet the principles of equity, effectiveness and transparency that should be the rule with aid allocation (as explained in Guillaumont 2008). It could then become more consistent with the aim it was initially supposed to reach.

The rationale of the new formulas of allocation presented below is simple. It is first to make the allocation more conducive to sustained growth and development by adding a structural vulnerability indicator besides the CPR. It is also to make it more equitable by introducing in the

\footnotetext{
6. It would be more relevant to compare allocations, commitments and disbursements on an average of several years, ideally the three years of an IDA cycle, but, as noted in the last footnote, the previous commitments are not made available, what weakens the transparency of the process.
} 
formula indicators of the structural handicaps to growth, namely a (low) level of human capital and, also for this same reason, structural economic vulnerability. It is finally to make the allocation process more transparent and consistent with aims of donors, by avoiding exceptions and treating the case of fragile states in an integrated and continuous framework.

\section{Two ways to address the previous issues.}

We propose two new formulas, both taking into account the structural vulnerability of the recipient countries, and their lack of human capital as well. The first one, closer to the present formula, can simply be seen as improving the measurement of "performance". In this case, the basis of the formula is not changed since the CPR will remain the major criterion. The second formula aims at balancing efficiency and equity criteria. In both cases the designed formula should allow one to treat the fragile states in a progressive and integrated framework. These formulas should be assessed with regard to the agreed aim of IDA to give a priority to Sub Sahara Africa. To be also underlined, any of the proposed formulas should be simple and transparent, then understandable by all stakeholders.

Each formula is illustrated by simulations (according to various weights given to the criteria) and the repartition of allocations between different categories of countries is presented (postconflict and reengaging countries, least-developed countries, low income countries, Sub-Sahara Africa). The simulations have been done for 2009. The stuctural vulnerability of countries has been measured by the Economic Vulnerability Index (EVI) and the level of human capital (by the Human Assets Index (HAl), both used at the UN for the identification of the Least Developed Countries. EVI is a composite indicator of seven components, three related to the size of the recurrent exogenous shocks, either natural or external, and four related to the exposure to these shocks ${ }^{7}$. HAl is a composite index of health and education components ${ }^{8}$. The traditional PBA as applied during the IDA 15 period (for 2009), with the special window for post-conflict and reengaging countries, is used as a benchmark ${ }^{9}$.

\section{Adding a political economy approach}

Any change in the criteria involves losers as well as winners. The decrease in the allocation to some countries, whatever its legitimacy, should be manageable and politically acceptable.. The view is that the losers could be compensated, at least provisionally, and decreasingly. This could be obtained thanks to additional resources flagged to that end in the replenishment process, or through saving IDA resources by financing blend countries by more or only by IBRD loans made more concessional (as suggested independently of a reform of the criteria by Ben Leo, 2010). In our simulations the range of resources thus needed is between $10 \%$ and $14 \%$ of the total

\footnotetext{
7.The components are the instability of exports of goods and services, the instability of agricultural production and the homelessness due to natural disasters for the shock components, the smallness of population (log) number, the remoteness from word markets, the export concentration and the share of agriculture, fisheries and forestry in GDP for the exposure to shock components (Guillaumont 2009).

8. The components of $\mathrm{HAl}$ are four indices respectively related to child survival, percentage of population undernourished, literacy rate and secondary enrolment ratio.

9. The same kind of simulations have been done for the allocations of the African Development Fund (Guillaumont, Guillaumont Jeanneney and Vencatachellum, 2009).
} 
amount of 2009 resources (and can be made decreasing over the three year cycle). It seems that the donors could manage this need of additional resources..

\section{Vulnerability in an augmented performance-based allocation}

Recall that the allocation of IDA or AFD resources is a three step process. First, resources are allocated using a formula based on performance, which is slightly different from one bank to the other. Then the financial terms of allocations are determined (grants or loans) and the allocated amounts are adjusted accordingly. Finally, for countries eligible for debt cancellation under the MDRI initiative, the cancelled debt service in the relevant fiscal year is netted out from that year's allocation. These netted-out amounts are then redistributed among aid eligible countries.

\section{The present formula}

The performance-based allocation formula used during the IDA 15 period is the following:

$$
P B A_{i}=\left(C P R_{i}\right)^{5 *}(G N I / P)^{-0,125 *} P_{i} \quad \text { (Formula 1) }
$$

with: $P B A_{i}$ the indicator of the allocation based on performance for a country $i$, $G N I / P$ the gross national income per capita for the year 2007 in U.S. dollars)

$P_{i}$ the population. The evaluation of country performance rating (CPR) is itself the sum of three indicators:

$C P R=0.24 C P I A_{A t o C}+0.68 C P I A_{D}+0.08 A R P P$

The CPIA (Country Policy and Institutional Assessment Index) is composed of sixteen indicators grouped into four categories: A) macroeconomic management, B) structural policies, C) social policies and finally D) public sector management and institutions, the latter referring to the concept of governance. Besides the two components related to the $C P I A$ the $C P R$ also encompasses a rating for each country's implementation performance based on the World Bank's Annual Report on Portfolio Performance (ARPP).

\section{An augmented measure of performance}

It is well known that policy is influenced by shocks, the recurrence of exogenous shocks weakening policy and institutions. Recent econometric results show that the CPIA is partly determined by the structural economic vulnerability and to a lesser extent by a low human capital (cf. Guillaumont, McGillivray and Wagner, communication to the same session of the ABCDE Conference). Moreover, as noted above, the CPIA is often pro-cyclical, and the CPR as well.

Then adding indicators of economic vulnerability and of low human capital to the usual CPR can simply be seen as a way to treating the endogeneity of the CPR (i.e. purging the CPR from the structural handicaps that are the economic vulnerability and low level of human capital). In other words controlling for the structural vulnerability makes the allocation more genuinely "performance based". 


\section{The implicit model is the following:}

If $C P R=-a \cdot E V I-b . L H A I+c+\operatorname{Residual}(C P R)$, with $(a>0 ; b>0)$

as the $C P R$ is a negative function of the economic vulnerability $E V I$ and of a low human capital $L H A I$ (with $L H A I=$ Max HAI $-H A I$ ).

Residual $(C P R)=C P R-(-a \cdot E V I-b \cdot L H A I+c)$

$=C P R+a \cdot E V I+b \cdot L H A I-c$.

The residual of $C P R$ can be seen as a more genuine measure of performance than the gross value of CPR. Noting ACPR this augmented measure of performance, we have:

$A C P R=C P R+a \cdot E V I+b \cdot L H A I-c$.

A rough estimation of the $2007 C P R$ as a function of the $E V I, H A I^{10}$ and the level of income per capita $(y)$, has been made on a cross section basis (74 IDA eligible countries) and with OLS (ordinary least squares), after transforming the $E V I$ and $H A I$ indices from their initial $O$ to 100 scale to 1 to 6 scale, as that of the $C P R$, and calling $L H A I$ the index of lack of human capital $(L H A I=6-H A I)$. The results are the following:

$C P R=-0.16 E V I-0.14 L H A I+0.09 \log y+3.51$

The $E V I$ and $H A I$ coefficients are significant at $1 \% .^{11}$

Using quintile regressions, the results of the estimation for the lowest quintile of CPIA give higher and even more significant coefficients (-0.20 and -0.19); coefficients for the next quintile are still higher than for the general regression, and still significant at $5 \% .{ }^{12}$

Thus adding structural vulnerability (through an index such EVI) and to a lesser extent the lack of human capital (through an index such as LHAI) in the PBA formula can simply be seen as an improved measurement of performance. It leads to an augmented performance allocation, more genuine and more transparent. The new formula is obtained by substituting an augmented country policy rating (ACPR) to the actual CPR, so that:

$P B A_{i}=\left(A C P R_{i}\right)^{5 *}(G N I / P)^{-0,125 *} P_{i} \quad$ (Formula 2)

which maintains the same weight to the augmented country policy rating as the country policy rating in the present formula and where ACPR is equal to:

$$
A C P R=\frac{1}{1+a+b} C P R+\frac{a}{1+a+b} E V I+\frac{b}{1+a+b} L H A I
$$

With $a=0.16$ and $b=0.14$ the respective weights of the three criteria are: $0.77 ; 0.12,0.11$ With $a=0.2$ and $b=0.19$ they become $0.72,0.14,0.14$.

10. calculated in 2009 at the UN for the last review of the list of least developed countries.

11. Estimations of the CPIA as a function of the same variables give even stronger coefficients for EVI and HAI respectively of -0.24 and -0.18 .

12. For the CPIA the coefficients obtained are -0.33 and -0.28 . 


\section{Simulations according to empirical weights}

As an illustration, we present a simulation according to the above formula 2 with the following weights: 0.70 for $C P R, 0.15$ for $E V I$ and for $L H A I$, since the $C P R$, as the $C P I A$, is an index on a 1 to 6 scale, the $E V I$ and $L H A I$, initially measured from 0 to 100 , have been transformed to be scaled consistently We do not include a special window for the post conflict and reengaging countries, as the aim is deleting the special window. Likewise we would delete most of the caps and floors included in the original formula. As we fear that lifting this constraint might require too many changes in the parameterization of the formula, we choose to only keep the special cap on India and on Pakistan. Accordingly, we suppress from the formula both the basic allocation and the cap on aid per capita. In order to maintain the consistency of our simulation results with regards to the suppression of these constraints, we produce a second set of results with an adjusted population weight. We choose to set the population exponent to 0.8 in those simulations. The "Augmented Performance Based Allocation" formulas (formulas 2 ) are then the following:

$P B A_{i}=\left(0.7 * C P R_{i}+0.15 * E V I_{i}+0.15 * L H A I_{i}\right)^{5} *\left(G N I p c_{i}\right)^{-0.125 * P_{i}} \quad$ (Simulation 1)

$P B A_{i}=\left(0.7 * C P R_{i}+0.15 * E V I_{i}+0.15 * L H A I_{i}\right)^{5 *}\left(G N I P c_{i}\right)^{-0.125 * P_{i}^{0.8}}$ (Simulation 1 bis)

The results of these simulations ( 1 and 1 bis) are presented in Table 1 for selected groups of countries. The choice of these groups fits the will of the World Bank to favour African and post-conflict countries. (Country results and by regional groups are given for simulation 1 bis in Appendix Table A1).

Aid surplus needed to avoid losses is: 853 millions of SDR (10.2\% of total allocation) according to simulation 1, and 1046 millions of SDR (12.5\% of total allocation) according to simulation 1 bis.

According to these results, the share of the least developed countries and Sub Sahara Africa is slightly increased, but that of post-conflict countries is reduced compared to the official allocations. To obtain a share allocated to post conflict countries closer to the official allocation, the weight given to EVI and LHAI should be increased.

\section{Simulations according to a priori weights}

As an illustration we present the results of two other simulations: the simulation 2 gives an equal weight to CPR and to EVl; the simulation 3 introduces simultaneously LHAI with an equal weight given to the three indicators.

$\begin{array}{ll}A C P R=0.5 C P R+0.5 E V I & \text { (simulation 2) } \\ A C P R=0.33 C P R+0.33 E V I+0.33 L H A I & \text { (simulation 3). }\end{array}$

As previously, we first keep floors, caps, and a population exponent equal to one. Second we delete cap and floor (except for the special cap on India and Pakistan), with a population exponent fixed to 0.8 (simulations 2 bis and 3 bis). 
First, let us consider the simulations with a population exponent equal to one (simulation 2 and 3 of table 1). With the simulation 2 the post conflict and reengaging countries obtain approximately the same share of allocations as with the present scheme, but of course there are significant deviations at the country level (for instance Côte d'Ivoire and Afghanistan receive less, because these countries have not a particularly high structural economic vulnerability). With the simulation 3 post-conflict countries and reengaging obtain a significantly higher share. .

The least developed countries, which are not only economically vulnerable, but also have a very low level of human capital, receive also and naturally the highest share with the third simulation that includes the HAI criterion. In both simulations Sub Sahara Africa receives more than the official allocation and all the more that EVI and HAI are given a higher weight.

Interesting enough, some countries that are not post-conflict (nor reengaging), but are economically vulnerable and as such likely to become fragile states, and are the losers in the present formula, receive more. Most of small size African countries are in this group. On the opposite some large and high CPR countries are losing (Kenya, Tanzania).

Simulations 2 bis and 3 bis provide the variant corresponding to a treatment more continuous and integrated of all countries, as they give an exponent to population lower than one (0.8) and delete all caps and floors. (Table 1).

The allocation shares are close to those of simulations 2 and 3. It suggests that a population exponent lower than one leads to avoiding the arbitrary thresholds due to base allocation and caps. The results that are the closest to the present allocation are obtained with the simulation 2bis. However they are not necessarily the best, since the simulation does not take into account the needs resulting from a low level of human capital. Taking these needs into account (simulation zbis) increases the shares of Sub Sahara Africa, post-conflict countries, and LDCs as well.

Finally the results show that it is necessary to give higher weights to EVI and LHAI than those given according to the ACPR. However it should be kept in mind that they are other reasons for taking EVI and HAI into account than researching to improve the performance measure, notably equity and transparency. 
Table 1 Shares of total allocations by groups of countries according to the "Augmented Performance Base Allocation" formulas (per cent) $>>$ (Arithmetic weights)

\begin{tabular}{|c|c|c|c|c|c|c|c|}
\hline & $\begin{array}{c}\text { Official } \\
\text { allocations }\end{array}$ & $\begin{array}{c}\text { Simulation } \\
\mathbf{1} \\
\text { Population } \\
\text { exponent } \\
\text { equal to } \\
\text { one }\end{array}$ & $\begin{array}{c}\text { Simulation } \\
\mathbf{1} \text { bis } \\
\text { Population } \\
\text { exponent } \\
\text { equal to } \\
0.8\end{array}$ & $\begin{array}{c}\text { Simulation } \\
\mathbf{2} \\
\text { Population } \\
\text { exponent } \\
\text { equal to } \\
\text { one }\end{array}$ & $\begin{array}{c}\text { Simulation } \\
\mathbf{2} \text { bis } \\
\text { Population } \\
\text { exponent } \\
\text { equal to } \\
0.8\end{array}$ & $\begin{array}{c}\text { Simulation } \\
\mathbf{3} \\
\text { Population } \\
\text { exponent } \\
\text { equal to } \\
\text { one }\end{array}$ & $\begin{array}{c}\text { Simulation } \\
\mathbf{3} \text { bis } \\
\text { Population } \\
\text { exponent } \\
\text { equal to } \\
0.8\end{array}$ \\
\hline $\begin{array}{l}\text { Post } \\
\text { conflict } \\
\text { and re- } \\
\text { engaging } \\
\text { countries }\end{array}$ & 9.65 & 7.21 & 7.61 & 8.74 & 8.99 & 15.44 & 15.88 \\
\hline $\begin{array}{l}\text { Least } \\
\text { developed } \\
\text { countries }\end{array}$ & 48.10 & 53.59 & 54.59 & 49.85 & 51.29 & 60.05 & 61.91 \\
\hline $\begin{array}{l}\text { Low } \\
\text { income } \\
\text { countries }\end{array}$ & 64.11 & 63.35 & 63.39 & 60.12 & 60.43 & 63.84 & 65.13 \\
\hline $\begin{array}{l}\text { Sub Sahara } \\
\text { Africa }\end{array}$ & 49.31 & 55.53 & 56.01 & 53.86 & 53.10 & 60.25 & 60.80 \\
\hline
\end{tabular}

NB: the total allocation is equal to 8345.20 millions of SDR.

\section{Vulnerability in an allocation balancing effectiveness and equity}

\section{Back to principles}

While the previous simulations stick to the present PBA, trying only to improve the measurement of performance by taking into account the structural handicaps it depends on, we now broaden our approach of PBA by starting from the even principles that should guide aid allocation: effectiveness, fairness and transparency. Effectiveness is still supposed to depend mainly from policy (captured by CPR), at least through the signal or incentive it offers, but to some extent it is also supposed to depend on structural vulnerability. Fairness is still supposed to be taken into account through the level of income per capita, but it is also supposed to depend on how the structural handicaps, vulnerability and low level of human capital, are taken into account so that aid allocation contributes to equalizing opportunities. To be recalled, structural vulnerability is both a factor of higher marginal effectiveness of aid and a structural handicap to be compensated.

For these reasons we have considered that a fair or well-balanced set of weights would be to weight equally the quality of policy, the structural vulnerability and the poverty level. However, not to too much deviate from the present formula, we have also examined other set of weights keeping a greater weight to the quality of policy (CPR).

As for transparency we have retained a structure of formula as simple as possible. All the four criteria have been measured on the same scale (from 1 to 6, as are presently the CPIA and the (PR). Thus the allocation to each country (share of total amount to be allocated) can be expressed as a weighted average of the four criteria. It makes the contribution of each criterion clearer than it is with the present formula.

\section{Methodological options}


The weighted average of the criteria can be arithmetic or geometric. Closer to the present practice is the geometric one. Even simpler is the arithmetic one, we prefer. The choice between the two of course is not only a matter of simplicity. With the geometric average the elasticity of allocation with respect to each criterion (let us say vulnerability) is constant and independent of the level of the other criteria (for instance policy), but the marginal contribution (or partial derivative) depends on the level of the criterion (decreasing with the level of the criterion: lower for a higher level of vulnerability), and on the level of the other criteria as well (the marginal impact of higher vulnerability will be higher if policy is good than if it is bad). With the arithmetic average the marginal contribution of each criterion is constant and independent of the level of the other criteria, but the elasticity depends on the level of the criterion (decreasing with the level of the criterion: lower for a higher level of vulnerability) and on the level of the other criteria as well (it will be lower for a better quality of policy). It can be argued that the marginal contribution is not only more understandable for stakeholders, but also more relevant because a higher vulnerability should have a same impact on allocation whatever the level of vulnerability. However the results appeared very near (Geometric results by groups of countries are given in Appendix Table A2)

As before we present simulations according to both population exponents. With the exponent 1 we maintain base allocation and caps, we delete them when the exponent is $0.8^{13}$. The "Effectiveness and Equity Based Allocation" formulas are then, with a decreasing weight given to CPR:

With a population exponent equal to one, the formulas 3 are the following:

$$
\begin{array}{lll}
P B A_{i}=\left(0.5 * C P R_{i}+0.25 * E V I_{i}+0.125 * L H A I_{i}+0,125 * L G N I_{p} c_{i}\right) * P_{i} & \text { (Simulation 1) } \\
P B A_{i}=\left(0.4 * C P R_{i}+0.3 * E V I_{i}+0.15 * L H A I_{i}+0,15 * L G N I P c_{i}\right) * P_{i} & \text { (Simulation 2) } \\
P B A_{i}=\left(0.33 * C P R_{i}+0.33 * E V I_{i}+0.16 * L H A I_{i}+0,16 * L G N I p c_{i}\right) * P_{i} & \text { (Simulation 3) }
\end{array}
$$

With a population exponent equal to 0.8 the formulas 3 become:

$$
\begin{aligned}
& P B A_{i}=\left(0.5 * C P R_{i}+0.25 * E V I_{i}+0.125 * L H A I_{i}+0,125 * L G N I p c_{i}\right) * P_{i}^{0.8} \text { (Simulation 1 bis) } \\
& P B A_{i}=\left(0.4 * C P R_{i}+0.3 * E V I_{i}+0.15 * L H A I_{i}+0,15 * L G N I p c_{i}\right) * P_{i}^{0.8} \quad \text { (Simulation 2 bis) } \\
& P B A_{i}=\left(0.33 * C P R_{i}+0.33 * E V I_{i}+0.16 * L H A I_{i}+0,16 * L G N I p c_{i}\right) * P_{i}{ }_{i}^{0.8} \text { (Simulation 3 bis) }
\end{aligned}
$$

The results by groups of countries are given in Table 2 (and the results by countries and by regional groups of countries for the simulations 3 bis in TableA 1 in Appendix)

13. Again except the cap for India and Pakistan 
Table 2 Shares of the total allocation by groups of countries according to the "Effectiveness and Equity Based Allocation" formulas (per cent)

\begin{tabular}{l|c|c|c|c|c|c|c}
\hline & Official & $\begin{array}{c}\text { Simulation } \\
\mathbf{1}\end{array}$ & $\begin{array}{c}\text { Simulation } \\
\mathbf{1} \text { bis }\end{array}$ & $\begin{array}{c}\text { Simulation } \\
\mathbf{2}\end{array}$ & $\begin{array}{c}\text { Simulation } \\
\mathbf{2} \text { bis }\end{array}$ & $\begin{array}{c}\text { Simulation } \\
\mathbf{3}\end{array}$ & $\begin{array}{c}\text { Simulation } \\
\mathbf{3} \text { bis }\end{array}$ \\
\hline $\begin{array}{l}\text { Post } \\
\text { conflict } \\
\text { and re- } \\
\text { engaging } \\
\text { countries }\end{array}$ & 9.65 & 9.92 & 10.68 & 10.24 & 11.01 & 10.44 & 11.21 \\
\hline $\begin{array}{l}\text { Least } \\
\text { developed } \\
\text { countries }\end{array}$ & 48.10 & 49.12 & 49.82 & 49.45 & 50.18 & 49.64 & 50.39 \\
\hline $\begin{array}{l}\text { Low } \\
\text { income } \\
\text { countries }\end{array}$ & 64.11 & 58.81 & 58.69 & 58.76 & 58.70 & 58.71 & 58.68 \\
\hline $\begin{array}{l}\text { Sub } \\
\text { Sahara } \\
\text { Africa }\end{array}$ & 49.31 & 48.98 & 49.44 & 49.26 & 49.72 & 49.44 & 49.88 \\
\hline
\end{tabular}

NB: the total allocation is equal to 8345.20 millions of SDR.

The aid surplus needed to avoid losses is equal for the first simulation to 1109 millions of SDR (1113 millions for the simulation 1bis), i.e. 13.3\% of total allocation, for simulation 2 et 2 bis to 1139 millions of SDR, i.e. $13.6 \%$ of total allocation, finally for the simulation 3 to 1158 millions of SDR (1165 millions of SDR for simulation 3bis) i.e. 13.8\% of total allocation (14\% for simulation 3 bis).

The last formula is our preferred one although the losses are $14 \%$ of the total allocation. Indeed the shares of the preferential countries (LDCs and Africa) are the highest of the simulations. The results by countries are available in the appendix (Table A1). The most loosing country is Vietnam. But there is also a reallocation among African countries; the countries with a relatively high CPIA are loosing (mainly Tanzania and Ghana). At the opposite fragile States (which are not post conflict or reengaging) would benefit from the reform.

\section{Concluding remarks}

\section{Summary results}

Starting from the present PBA, we have looked for a formula leading to an aid allocation better meeting the three principles of effectiveness, fairness and transparency, politically acceptable. Several formulas have been considered, deviating more and more from the present one, but all of them addressing the need to take into account the structural vulnerability of recipient countries. Closest to the present PBA is an "augmented PBA" where the measurement of performance by policy indicators is adjusted for the impact of vulnerability. The least close, and the simplest, is a weighted arithmetic average of effectiveness and equity criteria, including policy for effectiveness, income per capita and human capital for equity, and vulnerability both for effectiveness and equity. In all the cases simulations of IDA allocation (for 2009) have been run deleting most exceptions (cap, floor, special treatment of post-conflict countries) that make the present PBA unclear and little effective. Results show that an allocation of aid according to the principles 
recalled above can lead to preserve or generally increase the share allocated to the least developed countries, to Africa, as well as to post-conflict countries, these ones being now treated in an integrated framework (moreover the treatment of state fragility is thus preventive and not only curative). Anyway the choice of weights and simultaneously the preference given to poor, African or fragile states are of course a political choice. The total amount of losses induced for loser countries by the new formulas with the suggested weights remain in a range permitting a transitional compensation, under the condition that some additional resources can be mobilized.

Other modifications, more limited or complementary, are conceivable, that could be examined, but are here only noted.

\section{A possible complement: adding indicators of progress towards peace and security in the assessment of performance}

There has been several proposal to modify the content of the CPIA (not examined in this document) (cf for instance Kanbur 2004). Let us only consider an option that would be rather a complement of the refinement of the PBA proposed in this note. As far as the present CPR does not fairly assess the policy efforts made by the post-conflict and reengaging states, a specific index of policy assessment has been used for these countries, the post-conflict performance index (PCPI). It has been recently proposed to revise this index so that it becomes closer to the CPIA (IDA, 2009). In order to treat the case of the post-conflict countries in a more integrated and consistent manner, a solution would be to add to the CPIA an additional cluster, including only components that would be both dynamic (expressed as a variation) and related to peace and security. Change would be close to zero for most countries non post conflict, but hopefully positive for the post-conflict countries. A special window with a special index then would not be needed for them (with an arbitrary global envelope). Although it could then appear less useful to add an indicator of structural economic vulnerability into the formula, it would still be logical to do it for two reasons: (i) it is a means to make the allocation more genuinely performancebased, as explained above; (ii) it also makes the allocation preventive and not only curative of socio-political troubles.

Anyway it should be recognized that the most extreme cases of fragility and conflict cannot be treated only through an allocation formula and call for a special political response.

\section{Is compensatory finance a substitute?}

It is sometimes argued that vulnerability should be addressed by another way than aid allocation general criteria. It is to compensate countries when shocks occur. The ex post compensation of shocks is useful, but does not allow the international community to fully address the vulnerability issue. As evidenced by past experience, the schemes aiming at providing compensatory finance when a shortfall occurs in export earnings, although needed, are either too long to be mobilized and too conditional, or leading to wrong incentives. Also they risk being arbitrarily allocated. The same would hold true for vulnerability special windows such as the "crisis response window" presently designed by IDA (IDA 2010). An interesting exception is given by the so-called countercyclical loans (as implemented by AFD), where debt service is automatically linked to 
exogenous variable such as terms of trade, but it is only a partial and progressive answer.

More important, vulnerability ex ante allocation criterion has a preventive role, whereas compensatory finance, as well as fragile states windows, is only curative... It would probably be less costly and/or more effective to prevent collapses and conflicts than to overcome their effects.

\section{A crisis prevention window?}

However another alternative could be looked at, that is a substitute to the revision proposed above, if it was considered that the PBA cannot be changed, but only that a special window can be set up to address the risk of crises. The "crisis response window" designed by IDA is a window operating ex post or in a curative manner, for the countries facing acute shocks, with the usual limitations of this kind of instrument (trigger thresholds, implementation lags, ...). It should then be conceivable to add to this window a "Crisis prevention window" which would finance an additional allocation to all IDA eligible countries on a permanent and preventive basis, according to their level of structural economic vulnerability. It then means that vulnerability would be taken into account independently of performance, as it is the case in the allocation according to an arithmetic average, the last formula considered above.

\section{The proposal in a broader context}

The reform of the allocation formula used by IDA and similarly by other multilateral banks has not to be designed in a uniform manner for all development banks. In particular the vulnerability issue is of particular importance for Africa, a reason why a reform according to the lines here suggested, has been first examined for the African Development Fund. In that context the vulnerability issue was also addressed by a re-examination of the rules guiding the allocation for regional (multinational) purposes, a topic uncovered in this paper.

Moreover, the allocation formulas here proposed for multilateral development banks may not be for the other donors as relevant as it is for these banks, although the general principles are so. The rationale for a diversity of donors is a diversity of policies. But there is a need to insure a consistency between these various aid policies and the general principles of aid allocation. If the role of multilateral institutions was to make the global aid allocation consistent with theses principles (or with an optimal global allocation) their own rules of allocation would significantly differ from what they are now. 


\section{References}

- Amprou J., P. Guillaumont and S. Guillaumont Jeanneney (2007) "Aid Selectivity According to Augmented Criteria", The World Economy, Vol. 30, $\mathrm{n}^{\circ}$, p.733-763.

- Collier P. and B. Goderis (2009) "Does Aid Mitigate External Shocks?" Review of Development Economics, 13(3) 429-451. ,

- Chauvet, L. and P. Guillaumont (2004), "Aid and Growth Revisited: Policy, Economic Vulnerability and Political Instability" in B. Tungodden, N. Stern and I. Kolstad (eds.), Towards Pro-Poor Policies. Aid, Institutions and Globalisation, ABCDE 2003 Annual World Bank Conference on Development Economics Europe (New York: Oxford University Press).

- Chauvet L. and P. Guillaumont (2009), "Aid, Volatility and Growth Again: When Aid Volatility Matters and When it Does Not" UNU-WIDER, Review of Development Economics, 13(3), August, 452-463. .

\section{- Easterly W., R. Levine and D. Roodman} (2004) "Aid, Policies and Growth: Comment" American Economic Review, June, 94 (3), 774-780.

- Guillaumont P. (2008) “Adapting Aid Allocation Criteria to Development Goals" An Essay for the UN Development Cooperation Forum, FERDI Working Paper, May (also available on the web site of the UN).

- Guillaumont P. (2009a) "An Economic Vulnerability Index: Its Design and Use for International Development Policy", Oxford Development Studies, 37 (3), September, 193-228.

- Guillaumont P. (2009b) Caught in a trap. Identifying the least developed countries, Ferdi, Paris, Economica
- Guillaumont P. and L. Chauvet (2001), "Aid and Performance: a Reassessment", Journal of Development Studies, 37, 66-92.

\section{- Guillaumont P. and S.Guillaumont Jeanneney (1988) Stratégies de développement comparées, Zone franc et hors zone franc, Paris, Economica,}

\section{- Guillaumont P., S. Guillaumont} Jeanneney, and D. Vencatachellum (2009) "Accounting for Vulnerability of African Countries in Performance Based Aid Allocation", Working paper series, African Development Bank Group, Working paper $n^{\circ} 103$, October, 24 p.

\section{- Guillaumont P., M. McGillivray and} L.Wagner (2010) "Performance, Assessment, Vulnerability, Human Capital and the Allocation of Aid among Countries" ABCD Conference, Stockholm

- Hansen H. and F. Tarp (2001) "Aid and Growth Regressions" Journal of Development Economics, vol.64, p. 547-570.

- IDA (2009) “Post Conflict Performance Indicators: Recommendations of External Panel Review and Next Steps" October.

- IDA (2010) “Proposal for a Permanent Crisis Response Window in IDA" May.

- Kanbur R. (2005) «Réformer la formule: une modeste proposition pour inclure des critères de résultats dans les procédures d'allocation de l'aide de I'IDA » Paper for the $2^{\text {nd }}$ AFD-EUDN Conference Development Aid: Why and How?, Paris, November 25th, 2004, Revue d'économie du développement, 2-3, septembre 2005, p.79-108.

- Leo B. (2010a) “Leveraging World Bank Ressources for the Poorest: IDA Blended Financing Facility Proposal": Center for 
Global Development, Working Paper, 2146, June, www.cgdev.org

- Leo B. (2010b) “Inside the World Bank's Black Box Allocation System: How Well Does IDA Allocate Ressources to the Neediest and Most Vulnerable Countries?" Center for Global Development, Working Paper, 216, June, www.cgdev.org

- Michaïlof S. (2005), «Réformer la formule: commentaires. Une modeste vue des tranchées ", Paper for the $2^{\text {nd }}$ AFD-EUDN Conference on "Development Aid: Why and How?", Paris, 25 November 2004, Revue d'économie du développement, 2-3, septembre 2005, p. 109-118.

- Rawls J. (1971), A Theory of Justice, Cambridge, MA. Harvard University Press.

- Roemer J.E. (1998), Equality of Opportunity, Cambridge, MA: Harvard University Press.

- Roodman (2007) “The Anarchy of Numbers: Aid, Development and Cross-country Empirics", World Bank Economic Review, 21 (2) 255-277.

- World Bank (2006) Equity and development, World Development Report, Washington DC. 


\section{Appendix}

Table A1 Simulation results for:

$P B A_{i}=\left(0.7 * C P R_{i}+0.15 * E V I_{i}+0.15 * L H A I_{i}\right)^{5 *}\left(G N I P c_{i}\right)^{-0,125 * P_{i} 0.8 \quad \text { (Formula 2) }}$ $P B A_{i}=\left(0.33 * C P R_{i}+0.33 * E V I_{i}+0.16^{*} L H A I_{i}+0,16 * L G N I P c_{i}\right) * P_{i}^{0.8}$ (Formula 3)

\begin{tabular}{|c|c|c|c|c|c|}
\hline \multicolumn{2}{|c|}{ Millions of SDR } & \multicolumn{2}{|c|}{ Formula 2} & \multicolumn{2}{|c|}{ Formula 3} \\
\hline & $\begin{array}{l}\text { Official } \\
\text { Allocation }\end{array}$ & $\begin{array}{l}\text { Simulation } \\
1 \text { bis }\end{array}$ & Difference & $\begin{array}{c}\text { Simulation } \\
3 \text { bis }\end{array}$ & Difference \\
\hline \multicolumn{6}{|l|}{ Sub Sahara Africa } \\
\hline Angola & 67,90 & 70,08 & 2,18 & 110,42 & 42,52 \\
\hline Benin & 56,00 & 84,15 & 28,15 & 68,78 & 12,78 \\
\hline Burkina Faso & 125,70 & 185,42 & 59,72 & 114,32 & $-11,38$ \\
\hline Burundi & 60,40 & 63,63 & 3,23 & 57,07 & $-3,33$ \\
\hline Cameroon & 68,20 & 89,88 & 21,68 & 115,75 & 47,55 \\
\hline Cape Verde & 8,60 & 10,28 & 1,68 & 6,89 & $-1,71$ \\
\hline Central African Republic & 10,10 & 11,37 & 1,27 & 24,53 & 14,43 \\
\hline Chad & 12,60 & 48,57 & 35,97 & 76,64 & 64,04 \\
\hline Comoros & 1,90 & 3,65 & 1,75 & 7,47 & 5,57 \\
\hline $\begin{array}{l}\text { Congo, Democratic } \\
\text { Republic of }\end{array}$ & 280,10 & 219,50 & $-60,60$ & 289,92 & 9,82 \\
\hline Congo, Republic of & 17,30 & 11,55 & $-5,75$ & 23,57 & 6,27 \\
\hline Cote d'Ivoire & 85,20 & 46,99 & $-38,21$ & 100,35 & 15,15 \\
\hline Eritrea & 15,20 & 27,66 & 12,46 & 37,55 & 22,35 \\
\hline Ethiopia & 518,00 & 562,80 & 44,80 & 398,08 & $-119,92$ \\
\hline Gambia, the & 3,80 & 15,16 & 11,36 & 13,96 & 10,16 \\
\hline Ghana & 323,40 & 278,82 & $-44,58$ & 170,46 & $-152,94$ \\
\hline Guinea & 6,40 & 25,39 & 18,99 & 46,83 & 40,43 \\
\hline Guinea-Bissau & 4,20 & 13,53 & 9,33 & 16,67 & 12,47 \\
\hline Kenya & 266,00 & 204,22 & $-61,78$ & 214,62 & $-51,38$ \\
\hline Lesotho & 14,10 & 23,55 & 9,45 & 21,20 & 7,10 \\
\hline Liberia & 29,40 & & & & \\
\hline Madagascar & 45,40 & 64,23 & 18,83 & $-0,85$ & $-46,25$ \\
\hline Malawi & 92,70 & 151,79 & 59,09 & 100,69 & 7,99 \\
\hline Mali & 137,00 & 195,84 & 58,84 & 124,10 & $-12,90$ \\
\hline Mauritania & 2,80 & 14,48 & 11,68 & 17,77 & 14,97 \\
\hline Mozambique & 142,90 & 243,20 & 100,30 & 151,52 & 8,62 \\
\hline Niger & 65,10 & 140,53 & 75,43 & 103,25 & 38,15 \\
\hline Nigeria & 664,90 & 617,94 & $-46,96$ & 704,51 & 39,61 \\
\hline Rwanda & 81,80 & 142,28 & 60,48 & 73,23 & $-8,57$ \\
\hline Sao Tome and Principe & 1,50 & 1,88 & 0,38 & 2,44 & 0,94 \\
\hline Senegal & 101,70 & 131,80 & 30,10 & 97,86 & $-3,84$ \\
\hline Sierra Leone & 21,90 & 53,69 & 31,79 & 48,40 & 26,50 \\
\hline Somalia & 0,00 & & & & \\
\hline Sudan & 0,00 & 82,24 & 82,24 & 200,04 & 200,04 \\
\hline
\end{tabular}




\begin{tabular}{l|r|r|r|r|r}
\hline Tanzania & 431,00 & 396,86 & $-34,14$ & 223,55 & $-207,45$ \\
\hline Togo & 28,60 & 18,27 & $-10,33$ & 41,91 & 13,31 \\
\hline Uganda & 250,40 & 294,28 & 43,88 & 185,57 & $-64,83$ \\
\hline Zambia & 73,20 & 128,39 & 55,19 & 110,18 & 36,98 \\
\hline Zimbabwe & 0,00 & & & & \\
\hline & 4115,40 & 4673,88 & 558,48 & 4165,94 & 50,54 \\
\hline & $49.31 \%$ & $56.01 \%$ & & $49.88 \%$ & \\
\hline
\end{tabular}

\section{East Asia and Pacific}

\begin{tabular}{l|r|r|r|r|r}
\hline Cambodia & 39,30 & 71,81 & 32,51 & 103,08 & 63,78 \\
\hline Kiribati & 0,00 & 0,00 & 0,00 & $-0,06$ & $-0,06$ \\
\hline Lao People's & 21,80 & 39,71 & 17,91 & 52,57 & 30,77 \\
Democratic Republic & & & & & \\
\hline Mongolia & 20,30 & 24,32 & 4,02 & 24,50 & 4,20 \\
\hline Myanmar & 0,00 & & & & \\
\hline Papua New Guinea & 25,40 & 41,23 & 15,83 & 50,25 & 24,85 \\
\hline Samoa & 3,80 & 4,21 & 0,41 & 2,95 & $-0,85$ \\
\hline Solomon Islands & 3,90 & 5,04 & 1,14 & 7,97 & 4,07 \\
\hline Timor-Leste & 3,00 & 5,05 & 2,05 & 9,51 & 6,51 \\
\hline Tonga & 1,50 & 0,86 & $-0,64$ & 1,41 & $-0,09$ \\
\hline Vanuatu & 2,50 & 2,84 & 0,34 & 3,50 & 1,00 \\
\hline Vietnam & 750,10 & 360,19 & $-389,91$ & 390,50 & $-359,60$ \\
\hline & 871,60 & 554,80 & $-316,80$ & 646,17 & $-225,43$ \\
\hline & $10.44 \%$ & $6.65 \%$ & & $7.77 \%$ & \\
\hline
\end{tabular}

\section{Europe}

and Central Asia

\begin{tabular}{l|r|r|r|r|r}
\hline Armenia & 34,80 & 32,32 & $-2,48$ & 25,23 & $-9,57$ \\
\hline Azebaijan & 41,80 & 46,30 & 4,50 & 56,23 & 14,43 \\
\hline Bosnia-Herzegovina & 23,00 & 16,94 & $-6,06$ & 24,32 & 1,32 \\
\hline Georgia & 47,80 & 67,00 & 19,20 & 40,09 & $-7,71$ \\
\hline Kosovo & 0,00 & & & & \\
\hline Kyrgyz Republic & 25,60 & 29,46 & 3,86 & 42,56 & 16,96 \\
\hline Moldova & 29,30 & 25,76 & $-3,54$ & 28,48 & $-0,82$ \\
\hline Tajikistan & 19,50 & 29,34 & 9,84 & 47,78 & 28,28 \\
\hline Uzbekistan & 63,70 & 51,89 & $-11,81$ & 135,55 & 71,85 \\
\hline & 285,50 & 299,01 & 13,51 & 400,25 & 114,75 \\
\hline & $3.42 \%$ & $3.58 \%$ & & $4.83 \%$ & \\
\hline
\end{tabular}

Middle East

and North Africa

\begin{tabular}{l|c|c|c|c|c}
\hline Djibouti & 3,60 & 8,13 & 4,53 & 9,52 & 5,92 \\
\hline Yemen, Republic of & 95,30 & 125,74 & 30,44 & 151,65 & 56,35 \\
\hline & 98,90 & 133,87 & 34,97 & 161,16 & 62,26 \\
\hline & $1.19 \%$ & $1.60 \%$ & & $1.93 \%$ & \\
\hline
\end{tabular}

Latin America

and the Carribean

\begin{tabular}{l|r|r|r|r|c}
\hline Bolivia & 37,60 & 36,77 & $-0,83$ & 46,84 & 9,24 \\
\hline Dominica & 1,40 & 1,57 & 0,17 & 1,34 & $-0,06$ \\
\hline Grenada & 2,10 & 1,78 & $-0,32$ & 1,66 & $-0,44$ \\
\hline
\end{tabular}




\begin{tabular}{l|c|c|c|c|c}
\hline Guyana & 2,00 & 2,08 & 0,08 & 5,04 & 3,04 \\
\hline Haiti & 52,80 & 61,80 & 9,00 & 85,55 & 32,75 \\
\hline Honduras & 41,80 & 38,06 & $-3,74$ & 38,54 & $-3,26$ \\
\hline Nicaragua & 33,30 & 39,14 & 5,84 & 40,29 & 6,99 \\
\hline St. Lucia & 3,30 & 3,43 & 0,13 & 2,43 & $-0,87$ \\
\hline $\begin{array}{l}\text { St. Vincent and the } \\
\text { Grenadines }\end{array}$ & 2,40 & 2,18 & $-0,22$ & 1,81 & $-0,59$ \\
\hline & $\mathbf{1 7 6 , 7 0}$ & $\mathbf{1 8 6 , 8 0}$ & $\mathbf{1 0 , 1 0}$ & $\mathbf{2 2 3 , 5 0}$ & $\mathbf{4 6 , 8 0}$ \\
\hline & $\mathbf{2 . 1 2} \%$ & $\mathbf{2 . 2 4 \%}$ & & $\mathbf{2 . 6 9 \%}$ & \\
\hline
\end{tabular}

South Asia

\begin{tabular}{l|r|r|r|r|r}
\hline Afghanistan & 154,90 & 99,56 & $-55,34$ & 158,83 & \multicolumn{1}{|c}{3,93} \\
\hline Bangladesh & 783,00 & 543,99 & $-239,01$ & 686,84 & $-96,16$ \\
\hline Bhutan & 8,00 & 12,98 & 4,98 & 7,97 & $-0,03$ \\
\hline India & 969,70 & 984,66 & 14,96 & 991,52 & 21,82 \\
\hline Maldives & 3,70 & 4,14 & 0,44 & 4,09 & 0,39 \\
\hline Nepal & 156,50 & 156,83 & 0,33 & 166,13 & 9,63 \\
\hline Pakistan & 617,10 & 626,60 & 9,50 & 630,96 & 13,86 \\
\hline Sri Lanka & 104,20 & 74,57 & $-29,63$ & 108,33 & 4,13 \\
\hline & 2797,10 & 2503,34 & $-293,76$ & 2754,68 & $-42,42$ \\
\hline & $33.52 \%$ & $30.00 \%$ & & $32.97 \%$ & \\
\hline
\end{tabular}

In grey, post conflict and reengaging countries

Table A 2 Shares of the total allocation by groups of countries according to the "Effectiveness and Equity Based Allocation" formulas

\begin{tabular}{|c|c|c|c|c|c|c|c|}
\hline & Official & $\begin{array}{c}\text { Simulation } \\
1\end{array}$ & $\begin{array}{c}\text { Simulation } \\
2\end{array}$ & $\begin{array}{c}\text { Simulation } \\
3\end{array}$ & $\begin{array}{c}\text { Simulation } \\
\mathbf{1} \text { bis }\end{array}$ & $\begin{array}{c}\text { Simulation } \\
2 \text { bis }\end{array}$ & $\begin{array}{c}\text { Simulation } \\
\text { 3 bis }\end{array}$ \\
\hline $\begin{array}{l}\text { Post conflict } \\
\text { an re- } \\
\text { engaging } \\
\text { countries }\end{array}$ & $9,65 \%$ & $9,83 \%$ & $10,19 \%$ & $10,42 \%$ & $10,61 \%$ & $10,98 \%$ & $11,21 \%$ \\
\hline $\begin{array}{l}\text { Least } \\
\text { developed } \\
\text { countries }\end{array}$ & $48,10 \%$ & $49,41 \%$ & $49,77 \%$ & $49,95 \%$ & $50,22 \%$ & $50,64 \%$ & $50,84 \%$ \\
\hline $\begin{array}{l}\text { Low income } \\
\text { countries }\end{array}$ & $64,11 \%$ & $58,39 \%$ & $58,28 \%$ & $58,19 \%$ & $58,26 \%$ & $58,22 \%$ & $58,16 \%$ \\
\hline Africa & $49,31 \%$ & $48,95 \%$ & $49,29 \%$ & $49,45 \%$ & $49,31 \%$ & $49,63 \%$ & $49,78 \%$ \\
\hline $\begin{array}{l}\text { East Asia } \\
\text { and Pacific }\end{array}$ & $10,44 \%$ & $8,10 \%$ & $7,92 \%$ & $7,82 \%$ & $7,99 \%$ & $7,85 \%$ & $7,77 \%$ \\
\hline $\begin{array}{l}\text { Europe and } \\
\text { Central Asia }\end{array}$ & $3,42 \%$ & $3,85 \%$ & $3,79 \%$ & $3,77 \%$ & $4,97 \%$ & $4,88 \%$ & $4,84 \%$ \\
\hline $\begin{array}{l}\text { Middle East } \\
\text { and North } \\
\text { Africa }\end{array}$ & $1,19 \%$ & $1,76 \%$ & $1,77 \%$ & $1,78 \%$ & $1,95 \%$ & $1,97 \%$ & $1,98 \%$ \\
\hline $\begin{array}{l}\text { Latin } \\
\text { America } \\
\text { and the } \\
\text { Caribbean }\end{array}$ & $2,12 \%$ & $1,96 \%$ & $1,95 \%$ & $1,94 \%$ & $2,77 \%$ & $2,74 \%$ & $2,73 \%$ \\
\hline South Asia & $33,52 \%$ & $35,46 \%$ & $35,37 \%$ & $35,32 \%$ & $33,08 \%$ & $33,01 \%$ & $32,98 \%$ \\
\hline
\end{tabular}

Notes: The total allocation is equal to 8345.20 millions of SDR. 


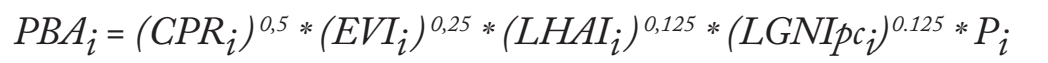
(Simulation 1) $\left.P B A_{i}=\left(C P R_{i}\right)^{0,4 *}\left(E V I_{i}\right)^{0,3 *}\left(L H A I_{i}\right)^{0,15 *(L G N I p c}\right)^{0.15 * P_{i}}$ (Simulation 2)

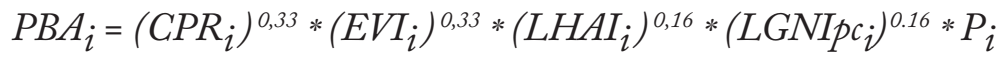
(Simulation 3)

$\left.P B A_{i}=\left(C P R_{i}\right)^{0,5 *\left(E V I_{i}\right.}\right)^{0,25 *\left(L H A I_{i}\right)^{0,125 *}\left(L G N I p c_{i}\right)^{0.125 * P_{i} 0.8}}$ (Simulation 1 bis)

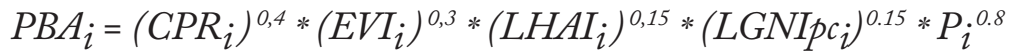
(Simulation 2 bis)

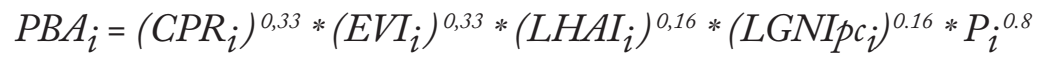
(Simulation 3 bis)

Aid surplus needed to avoid losses: 1087 millions of SDR (13\% of total allocation) for simulation 1, 1119 millions of SDR (13.4\% of total allocation) for simulation 2 and 1141 millions of SDR (13.6\% of total allocation).

Aid surplus needed to avoid losses: 1098 millions of SDR ( $13.1 \%$ of total allocation) for simulation 1, 1126 millions of SDR (13.5\% of total allocation) for simulation 2, 1153 millions of SDR (13.8\% of total allocation), again little increasing. 


\section{$\mathrm{F}=\mathrm{x}_{\mathrm{Di}}$}

Créée en 2003, la Fondation pour les études et recherches sur le développement international vise à favoriser la compréhension du développement économique international et des politiques qui l'influencent.

\section{$\hookrightarrow$ contact}

www.ferdi.fr

contact@ferdi.fr

+33 (0)4 73177530 